\title{
Real-life data on safety and efficacy of autologous stem cell transplantation in elderly patients with multiple myeloma
}

\author{
Carolina Marini ${ }^{1}$ (I) Tânia Maia $^{1} \cdot$ Rui Bergantim ${ }^{1,2} \cdot$ Jorge Pires $^{1} \cdot$ Eliana Aguiar $^{1} \cdot$ José Eduardo Guimarães $^{1,2}$. \\ Fernanda Trigo ${ }^{1}$
}

Received: 22 February 2018 / Accepted: 17 October 2018 / Published online: 27 October 2018

(C) The Author(s) 2018

\begin{abstract}
Autologous stem cell transplantation (ASCT) is still debatable in treatment of patients over 65 years with multiple myeloma (MM). We performed a retrospective analysis of newly diagnosed MM patients who underwent ASCT between January 2010 and July 2016. A non-transplanted group with similar clinical characteristics, aged 65-70 years old, diagnosed and treated in the same timeline was used for comparison. We analyzed a total of 155 patients, 132 of which underwent ASCT ( $\leq 65$ years, $n=103$, median 56 years; $>65$ years, $n=29$, median 67 years) and 23 non-transplanted (median 68 years). Conditioning consisted of melphalan $200 \mathrm{mg} / \mathrm{m}^{2}$ (MEL200) in younger patients and melphalan $140 \mathrm{mg} / \mathrm{m}^{2}$ (MEL140) in half of elderly patients. Stratifying by age, there were no statistically significant differences concerning transplant-related myelotoxicity and non-hematopoietic toxicity; however, elderly patients conditioned with MEL200 had higher needs of transfusional support and more days of intravenous antibiotics. Those patients also had higher needs of transfusional support, higher grade of mucositis $(p=0.028)$, and more days of intravenous antibiotics $(p=0.019)$ than the elderly transplanted with MEL140. Global transplant-related mortality was 3.8\%. Survival was not influenced by age. Non-transplanted elderly patients had comparable disease features, and induction response was similar in both groups (before ASCT in the transplanted cohort). Survival of transplanted elderly patients was superior to non-transplanted (OS, 59 months vs 30 months, $p=0.037$; EFS, 45 months vs 27 months, $p=0.014$ ). Selected elderly patients when transplanted have similar disease response and survival as younger patients. A higher dose of melphalan has more toxicity, but it is globally a well-tolerated procedure.
\end{abstract}

Keywords Multiple myeloma $\cdot$ Elderly $\cdot$ Autologous transplantation

\section{Introduction}

Multiple myeloma (MM) is mainly a disease of the elderly [1, 2]. On the one hand, the lengthening of life expectancy is related to an increase in the incidence of oncological diseases, and on the other hand, the improvement of diagnostic acuity and new therapeutic options on MM has led to a longer survival of elderly patients from median 19 months (in 1973) to 6.1 years (in 2004) [1, 3, 4]. A Mayo Clinic study [2] confirmed a significant increase in cases diagnosed in older age groups when comparing to the 1950 s and early 2000 s, with

Carolina Marini

carolinamarini@gmail.com

1 Centro Hospitalar de São João, Porto, Portugal

2 Faculdade de Medicina da Universidade do Porto, Porto, Portugal the median age at diagnosis of MM increasing from 70 to 74 years, as well as doubling the proportion of newly diagnosed patients aged 80 years or older.

Over the last two decades, there were significant advances in understanding MM disease biology and in development of several new drugs that allowed a paradigm shift from a palliative intent towards the active management of the disease aiming to prolong event-free survival (EFS) and overall survival (OS) [1]. Nowadays, induction followed by autologous stem cell transplantation (ASCT) after high-dose melphalan conditioning continues the standard treatment for MM patients under the age of 65 years [1,5-7]. Some studies suggest that age at the time of transplant does not have prognostic significance on outcome after ASCT [8,9], but its safety and efficacy remain uncertain for patients over that age [9-16].

Aging determines a progressive deterioration of physiological reserves and endurance that may increase morbidity and mortality, jeopardizing the effectiveness of ASCT as part of 
treatment options in MM. Despite these concerns, studies show there is a blatant benefit in survival for transplanted elderly patients [14, 17-22], even in analysis adjusted to performance status, comorbidities, and disease stage [20] and after the introduction of novel agents for induction chemotherapy $[14,19,21]$. Therefore, it is imperative to evaluate transplant toxicity in an advanced age. Despite lacking randomized data in the elderly population, recent data reveal that ASCT is becoming more used over 65 years old $[12,19]$, allowing to determine its efficacy and toxicity in the real-life context for this population.

\section{Objective}

The main goal of this analysis is the evaluation of ASCT's toxicity in elderly patients ( $>65$ years old) when compared to a younger cohort ( $\leq 65$ years old). Secondary endpoints included the efficacy of ASCT and evaluation of OS and progression-free survival (PFS) in the transplanted.

\section{Methods}

\section{Patients and risk stratification}

Retrospective analysis of $132 \mathrm{MM}$ patients consecutively submitted to ASCT between January 2010 and July 2016, at the Department of Hematology of Centro Hospitalar São João (Porto, Portugal). Patients were stratified by age into two groups: group $1, \leq 65$ years old, and group $2,>65$ years old. Data from 65- to 70-year-old patients diagnosed in this same calendar period who were not transplanted were used for comparison (group 3). Exclusion criteria included the following: plasma cell leukemia or amyloidosis at diagnosis, death during induction therapy in patients with indication for ASCT or during the first line of treatment in patients with no indication for ASCT who did not complete all cycles, patients in palliative care. This center also received patients referred for ASCT in whom diagnosis and induction therapy were performed at a different hospital. For risk stratification, we used the International Staging System (ISS) [23], Durie Salmon Staging System (DS) [24], and fluorescence in situ hybridization (FISH) for deletion $17 \mathrm{p}$, deletion $1 \mathrm{p}$, gain of 1q, deletion $13 \mathrm{q}$, deletion $16 \mathrm{q}$, deletion $14 \mathrm{q}$, and translocations $t(4 ; 14)$, $t(11 ; 14)$, and $t(14 ; 16)$. The threshold cytogenetics abnormalities were set at $10 \%$.

\section{Transplant eligibility}

Indication for ASCT followed our center protocol in which eligibility criteria include a performance status (PS) ECOG $\leq$ 2 and no significant comorbidities, evaluated by echocardiogram, respiratory functional studies, and also daily life performance information reported by patient's attending physician.

\section{Induction therapy and stem cell mobilization}

Patients received two to seven cycles of induction therapy before stem cell mobilization. Induction therapy was applied according to the local protocol of our center and referring institutions. Peripheral hematopoietic progenitor cells were mobilized with cyclophosphamide $\left(4 \mathrm{~g} / \mathrm{m}^{2}\right)$ and granulocyte colony-stimulating factor (G-CSF) $10 \mathrm{mcg} / \mathrm{kg}$ twice a day or G-CSF alone if patients had less than complete response or complete response after induction therapy, respectively.

\section{Conditioning for transplant}

Conditioning regimen consisted of melphalan at high dose $200 \mathrm{mg} / \mathrm{m}^{2}$ (MEL200) or with reduced dose 100 or $140 \mathrm{mg} /$ $\mathrm{m}^{2}$ (rMEL) according to the presence of organ dysfunctions (creatinine clearance $\leq 40 \mathrm{~mL} / \mathrm{min}$ or subjective evaluation of the patient's ability to receive high-dose melphalan). Prophylactic care included antiviral and antifungal prophylaxis, thromboprophylaxis before thrombocytopenia, and Caphosol® for mucositis prophylaxis.

\section{Assessment of transplant-related toxicity}

For transplant safety assessment, data were collected on hematologic toxicity (transfusion needs, time in days until peripheral neutrophil, and platelet count recovery), mucositis (grade, use and duration in days of intravenous morphine), and infection (number of days of fever, antibiotics used, days under antibiotics), days of hospitalization, and need for intensive care during the transplant procedure. Engraftment was defined by absolute neutrophil count (ANC) $\geq 0.5 \times 109 / \mathrm{L}$ for three consecutive days, and platelet count $\geq 20 \times 109 / \mathrm{L}$ unsupported by platelet transfusions in the last 7 days. Treatment-related mortality (TRM) was defined as death during the first 100 days after ASCT.

\section{Assessment of complications among elderly patients}

Description and comparison of complications according to Common Terminology Criteria for Adverse Events (CTCAE) [25] in elderly patients, transplanted or not, in the first 12 months after beginning treatment. Inpatient days due to complications accounted for excess days in treatmentrelated hospitalizations and complications severe enough to require hospitalization. 


\section{Assessment of treatment efficacy and survival}

Treatment response was assessed according to the IMWG guidelines [26]. It was carried out after induction therapy in all groups and 100 days after ASCT in transplanted patients.

Evaluation of overall survival (OS) and event-free survival (EFS) was performed by age and transplant status. EFS was defined as the time from ASCT to relapse/progression or death from the disease. OS was defined as the time from ASCT to death from any cause.

\section{Statistical analysis}

Statistical analysis was performed using SPSS® v.20 [27]. Normal distribution was characterized by skewness and kurtosis for psychometric variables and by Shapiro-Wilk and Kolmogorov-Smirnov tests $(p>0.01)$. Regarding EFS, we applied nonparametric tests and survival curves according to the Kaplan-Meyer method with the log-rank test to identify differences between groups. For OS, hazard ratio (HR) was calculated according to Cox regression analysis for age and melphalan dose effect. A confidence interval was defined at $95 \%$.

\section{Ethics committee analysis}

This study has been evaluated and approved by our ethics committee, the Ethics Committee for Health of Centro Hospitalar de São João/Faculty of Medicine of Oporto University.

\section{Results}

\section{Baseline clinical and laboratory features}

Patient's demographics, disease characteristics, and risk stratification by age group are summarized in Table 1 . There was a total of $155 \mathrm{MM}$ patients newly diagnosed in the defined period, 103 of which in group 1, 29 in group 2, and 23 in group 3. By Charlson comorbidity index, non-transplanted elderly patients had significantly higher scores $\geq 3(p=0.02)$ when compared to transplanted elderly patients and also higher scores when compared to younger patients $(p=$ $0.013)$. No statistical difference in disease characteristics or staging ( $p>0.05$ in all parameters) was found between the three groups.

\section{Treatment, response to induction, and mobilization}

Regarding treatment protocol selection (Table 2), there was no statistical difference in choice of novel agents according to age $(p=0.17)$ or ASCT status $(p=0.58)$ (Table 1$)$. Concerning treatment response after induction, $73 \%$ of younger transplanted patients had at least very good partial response (VGPR) as well as 69\% of the elderly transplanted and $65 \%$ of the elderly non-transplanted patients (Table 2). Despite these differences, it was not statistically relevant, either in the transplanted group $(p=0.72)$ or in the non-transplanted group $(p=0.77)$ when compared to its age-adjusted cohort. Considering transplanted patients, age did not correlate to the selection of mobilization regimen $(p=0.22)$, to the number of collected PBPCs $(p=0.09)$, or to the number of apheresis for appropriate collection $(p=0.55)$.

\section{Engraftment and transplant-related toxicity}

Evaluation of hematologic toxicity according to age subgroups (Table 3 ) revealed that elderly patients had the same median days of aplasia as the younger cohort. Concerning non-hematopoietic toxicity, there were no significant differences in all parameters, namely infection and mucositis. This was also verified when adjusting to the dose of melphalan.

However, when assessed by the dose of melphalan solely in the elderly group, older patients conditioned by MEL200 seem to have fewer days until neutrophil recovery but with a greater need for transfusion support. These patients had more mucositis (grade and need of support) and more days of antibiotics than the ones conditioned by rMEL. Five patients had to be admitted to intensive care unit ( 3 under 65 years old and 2 over 65 years old), four of them due to septic shock, and one patient for stroke and bronchiolitis obliterans with organizing pneumonitis. The median inpatient days were 21 (range 15 to $91)$, and there were no differences between groups $(p=0.19)$. Charlson comorbidity index did not affect transplant-related toxicity, either by age or by the dose of melphalan.

\section{Non-transplanted patients}

Evaluation of complications in transplanted and nontransplanted elderly patients (Table 4) revealed that transplanted patients had more incidence of complications $(p=0.02)$ and significantly more inpatient days due to these complications $(p=0.04)$. Infection was the most frequent complication, accounting for $40 \%$ in transplanted patients and $48 \%$ in non-transplanted patients. Regarding severity, transplanted patients had more grade $3-4$ complications $(p=0.043)$.

\section{Response at day 100 and survival}

After induction therapy, CR was achieved in $27 \%$ of transplanted patients. High-dose chemotherapy and ASCT increased the $\mathrm{CR}$ rate to $51 \%$. Response at day 100 posttransplant (Table 5) was significantly better than response after induction therapy $(p<0.01)$, with no relation to age. Approximately, a quarter of younger patients and a third of elderly patients had improvement in depth of post-transplant 
Table 1 Demographics and disease classification at diagnosis

\begin{tabular}{|c|c|c|c|}
\hline & $\leq 65$ years old & ASCT $>65$ years old & No $\mathrm{ASCT} \geq 65$ years old \\
\hline Age at diagnosis, years (median) & $56(36 ; 65)$ & $67(64 ; 70)$ & $68(65 ; 70)$ \\
\hline Age at transplant, years (median) & $56(37 ; 65)$ & $68(66 ; 70)$ & NA \\
\hline \multicolumn{4}{|l|}{ Gender } \\
\hline Male $(n)$ & $51(49 \%)$ & $21(72 \%)$ & $11(48 \%)$ \\
\hline Female $(n)$ & $52(51 \%)$ & $8(28 \%)$ & $12(52 \%)$ \\
\hline \multicolumn{4}{|l|}{ Performance status } \\
\hline \multicolumn{4}{|l|}{ ECOG } \\
\hline$\leq 2(n)$ & $103(100 \%)$ & $29(100 \%)$ & $19(82 \%)$ \\
\hline$>2(n)$ & 0 & 0 & $4(18 \%)$ \\
\hline \multicolumn{4}{|l|}{ Charlson score } \\
\hline $1-2(n)$ & $86(83 \%)$ & $18(62 \%)$ & $7(30 \%)$ \\
\hline $3-4(n)$ & $16(16 \%)$ & $10(35 \%)$ & $11(48 \%)$ \\
\hline$\geq 5(n)$ & $1(1 \%)$ & $1(3 \%)$ & $5(22 \%)$ \\
\hline \multicolumn{4}{|l|}{ CRAB } \\
\hline Calcium $>2.75 \mathrm{mmol} / \mathrm{L}(n)$ & $15(15 \%)$ & $5(18 \%)$ & $3(13 \%)$ \\
\hline Creatinine $>2 \mathrm{mg} / \mathrm{dL}(n)$ & $11(11 \%)$ & $4(16 \%)$ & $10(43 \%)$ \\
\hline Hemoglobin $<10$ g/dL $(n)$ & $38(37 \%)$ & $9(31 \%)$ & $12(52 \%)$ \\
\hline Bone disease $(n)$ & $74(71 \%)$ & $21(72 \%)$ & $12(66 \%)$ \\
\hline B2MICRO > $3.5 \mathrm{mg} / \mathrm{L}(n)$ & $40(43 \%)$ & $14(54 \%)$ & $14(88 \%)$ \\
\hline \multicolumn{4}{|l|}{ Monoclonal component } \\
\hline $\operatorname{IgG}(n)$ & $54(52 \%)$ & $13(45 \%)$ & $11(48 \%)$ \\
\hline $\operatorname{IgA}(n)$ & $19(18 \%)$ & $11(38 \%)$ & $6(26 \%)$ \\
\hline Light chains only $(n)$ & $18(17 \%)$ & $4(14 \%)$ & $6(26 \%)$ \\
\hline Other $(n)$ & $12(13 \%)$ & $1(3 \%)$ & 0 \\
\hline \multicolumn{4}{|l|}{ Staging ISS } \\
\hline $\mathrm{I}(n)$ & $39(38 \%)$ & $7(24 \%)$ & $3(13 \%)$ \\
\hline II $(n)$ & $32(31 \%)$ & $10(35 \%)$ & $4(17 \%)$ \\
\hline $\mathrm{III}(n)$ & $26(25 \%)$ & $10(35 \%)$ & $13(56 \%)$ \\
\hline Unknown $(n)$ & $6(6 \%)$ & $2(6 \%)$ & $3(14 \%)$ \\
\hline \multicolumn{4}{|l|}{ Cytogenetic risk } \\
\hline Standard $(n)$ & $30(29 \%)$ & $11(38 \%)$ & $4(17 \%)$ \\
\hline Intermediate $(n)$ & $24(23 \%)$ & $5(17 \%)$ & $10(43 \%)$ \\
\hline $\operatorname{High}(n)$ & $12(12 \%)$ & $2(7 \%)$ & $2(9 \%)$ \\
\hline Unknown $(n)$ & $37(36 \%)$ & $11(38 \%)$ & $7(31 \%)$ \\
\hline BM plasma cells (median) & $18(0 ; 80)$ & $10(0.5 ; 80)$ & $15(1 ; 86)$ \\
\hline
\end{tabular}

Charlson score is calculated at time of diagnosis; CRAB is acronym for calcium, renal, anemia, bone, for clinical classification of MM [28]; BM plasma cells is median percentage of plasma cells in bone marrow at diagnosis, by immunophenotype. Cytogenetic risk is defined by Mayo Stratification of Myeloma and Risk Adapted Therapy consensus guidelines 2013 (mSMART) [29] response (Graph 1). Autologous transplantation deepened the level of response as highlighted when comparing to ageadjusted non-transplanted patients $(p=0.05)$.

Five patients died during the transplant procedure $(n=3)$ or the first 100 days after ASCT $(n=2)$ resulting in a TRM of $3.8 \%$, all deaths related to infectious complications.

Data on progression and survival status were collected in September 2016 with a median follow-up of 30 months. Elderly patients had a median EFS of 45 months vs 59 months in younger patient group ( $p=0.63$, with no difference in OS
(HR 1.73, CI 0.81-3.70, $p=0.15)$ (Graph 2). Elderly patients conditioned with MEL200 had a median EFS of 62 months vs 45 months in elderly patients treated with a reduced dose of melphalan, however with no statistical significance $(p=0.79)$. There was no effect in OS according to melphalan dose in these patients (HR 0.80, CI 0.22-2.86, $p=0.73$ ) (Graph 3). When comparing elderly transplanted patients to nontransplanted patients, there is an essential difference in survival curves. There is an advantage of the transplanted group on EFS with a median time of 45 months vs 27 months on the 
Table 2 Therapy characteristics and response to induction therapy

\begin{tabular}{llll}
\hline & $\leq 65$ years old & $\begin{array}{l}\text { ASCT }> \\
65 \text { years old }\end{array}$ & $\begin{array}{l}\text { No ASCT } \geq \\
65 \text { years old }\end{array}$ \\
\hline Induction chemotherapy & $71(69 \%)$ & $22(76 \%)$ & $15(65 \%)$ \\
Bortezomib-based $(n)$ & $3(3 \%)$ & $3(10 \%)$ & $4(17 \%)$ \\
IMiD-based $(n)$ & $27(26 \%)$ & $4(14 \%)$ & $3(13 \%)$ \\
Bortezomib + IMiDs $(n)$ & $2(2 \%)$ & 0 & $1(5 \%)$ \\
Neither $(n)$ & & & $8(35 \%)$ \\
Response to therapy & $29(28 \%)$ & $7(24 \%)$ & $7(30 \%)$ \\
CR $(n)$ & $46(45 \%)$ & $13(45 \%)$ & $5(22 \%)$ \\
VGPR $(n)$ & $27(26 \%)$ & $9(31 \%)$ & $3(13 \%)$ \\
PR $(n)$ & $1(1 \%)$ & 0 & $3(13 \%)$ \\
Refractory $/$ stable $(n)$ & $13(12 \%)$ & $6(21 \%)$ & NA \\
$>2$ lines of treatment for better response $(n)$ & $8(3 ; 21)$ & $9(4 ; 20)$ & NA \\
Time to transplant $($ median months) & & & NA \\
Mobilization regimen & $78(76 \%)$ & $25(86 \%)$ & NA \\
HD-Cy + GCSF $(n)$ & $25(24 \%)$ & $4(14 \%)$ & NA \\
G-CSF only $(n)$ & $6.5(2.2 ; 35)$ & $5.0(1.6 ; 19)$ & $8(27 \%)$ \\
CD34+ collected (median $\left.\times 10^{6} / \mathrm{kg}\right)$ & $23(22 \%)$ & & \\
Number of apheresis $\geq 3$ & & & \\
\hline
\end{tabular}

$I M i D s$, immunomodulatory drugs; $H D$ - $C y$, high-dose cyclophosphamide; $G$-CSF, granulocyte colony-stimulating factor

non-transplanted group $(p=0.014)$. This advantage remains significant on OS (Graph 4).

\section{Discussion}

In our analysis, elderly patients have more toxicity with MEL200 when comparing to reduced doses of melphalan, yet these are manageable complications with the current supportive standard of care. Complications included increased demand for transfusions, support for mucositis, and need for antibiotics for infection control. It is noteworthy that elderly patients treated with MEL200 had less median days of aplasia, which may seem contradictory. Nonetheless, these patients received more supportive measures (higher number of transfused platelet units and erythrocyte concentrates) which may indicate a slower global recuperation. Non-transplanted elderly patients had fewer hospitalizations due to complications, and most of them had low severity, preserving ambulatory management of these patients which is a general aim when handling patients with no curative intent.
Table 3 Transplant-related toxicity by age, the dose of melphalan and in the elderly group

\begin{tabular}{llll}
\hline & $\leq 65$ vs $>65$ & $>65:$ rMEL vs MEL200 & MEL200: $\leq 65$ vs $>65$ \\
\hline Myelotoxicity & & & \\
Aplasia (median days) & 12 vs $12(p 0.55)$ & 12 vs $11(p 0.025)$ & 12 vs $11(p 0.051)$ \\
PLT recovery (median days) & 12 vs $12(p 0.74)$ & 12 vs $12(p 0.11)$ & 12 vs $12(p 0.43)$ \\
PLT support (median units) & 1 vs $2(p 0.32)$ & 1 vs $2(p 0.20)$ & 1 vs $2(p 0.06)$ \\
RBC support (median units) & 0 vs $0.5(p 0.32)$ & 0 vs $1(p 0.17)$ & 0 vs $1(p 0.06)$ \\
Non-hematopoietic toxicity-infection & 2 vs $2(p 0.86)$ & 1 vs $2(p 0.29)$ & 2 vs $2(p 0.30)$ \\
Fever (median days) & 147 vs $139(p 0.71)$ & 156 vs $129(p 0.52)$ & 145 vs $129(p 0.45)$ \\
CRP (median mg/L) & 2 vs $2(p 0.75)$ & 1 vs $2(p 0.17)$ & 2 vs $2(p 0.32)$ \\
Antibiotics (median number) & 9 vs $7(p 0.20)$ & 7 vs $11(p 0.019)$ & 9 vs $11(p 0.21)$ \\
Antibiotics (median days) & III vs III $(p 0.55)$ & II vs III $(p 0.028)$ & III vs III $(p 0.09)$ \\
Non-hematopoietic toxicity-mucositis & $55 \%$ vs $41 \%(p 0.18)$ & $28 \%$ vs $63 \%(p 0.12)$ & $56 \%$ vs $63 \%(p 0.75)$ \\
Grade (median) & 3 vs $0(p 0.13)$ & 0 vs $3(p 0.08)$ & 3 vs $3(p 0.61)$ \\
IV morphine (\% who need) & &
\end{tabular}


Table 4 Complications in elderly patients, transplanted or not

\begin{tabular}{lll}
\hline & ASCT $>65$ years old & No ASCT $\geq 65$ years old \\
\hline Median number of complications in 1 year & $4(0 ; 6)$ & $2(0 ; 7)$ \\
Median number of inpatient days due to complications & $8(0 ; 50)$ & $0(0 ; 53)$ \\
Type of complications by number of patients & & \\
Neuropathy $(n)$ & $9(31 \%)$ & $5(22 \%)$ \\
Thrombotic $(n)$ & $2(7 \%)$ & $3(13 \%)$ \\
Hemorrhagic $(n)$ & $2(7 \%)$ & $1(4 \%)$ \\
Infection $(n)$ & $28(96 \%)$ & $17(74 \%)$ \\
Mucositis $(n)$ & $24(82 \%)$ & 0 \\
Others $(n)$ & $5(17 \%)$ & $9(39 \%)$ \\
Grade of complications by number of events & & 55 \\
Number of events $(n)$ & 102 & $42(76 \%)$ \\
Grade 1-2 $(n)$ & $54(53 \%)$ & $13(24 \%)$ \\
Grade 3-4 $(n)$ & $48(47 \%)$ & \\
\hline
\end{tabular}

In the type of complications, the category "Others" includes cardiac, hepatic, endocrine, and cutaneous toxicities
There was no excess transplant-related mortality (TRM) in elderly patients and inpatient days were the same regardless of age despite higher toxicity, reinforcing there was an adequate control of complications. Even though autologous transplantation is a standard of care for multiple myeloma, age still plays an important role when pondering this intensification of treatment as questions are raised on the endurance of elderly patients to receive high-dose chemotherapy. It has been demonstrated in several studies that improvement of supportive care provides adequate control of complications [30], reducing discomfort associated with this procedure and even reducing TRM [12, 31]. Cheikh et al. [31] already hypothesized that improvement in supportive care, particularly the use of G-CSF and prophylactic care after intensive chemotherapy, had a positive effect reducing TRM; likewise, Auner et al. [12] observed a marked decrease in mortality throughout the decade 1991-2001, $\leq 2.4 \%$ in all age groups, but considerably higher in older than in younger patients;
Table 5 Conditioning and outcome after transplant

\begin{tabular}{llll}
\hline & $\leq 65$ years old & ASCT $>65$ years old & No ASCT $\geq 65$ years old \\
\hline Conditioning & & & \\
MEL200 $(n)$ & $101(98 \%)$ & $11(38 \%)$ & NA \\
MEL140 $(n)$ & $2(2 \%)$ & $15(52 \%)$ & NA \\
MEL100 $(n)$ & 0 & $3(10 \%)$ & NA \\
Response at day 100 & & & \\
CR $(\%)$ & $50(49 \%)$ & $17(59 \%)$ & NA \\
VGPR $(\%)$ & $39(38 \%)$ & $6(21 \%)$ & NA \\
PR $(\%)$ & $10(9 \%)$ & $4(14 \%)$ & NA \\
Refractory/stable $(\%)$ & $1(1 \%)$ & 0 & NA \\
Death at day $100(\%)$ & $3(3 \%)$ & $2(6 \%)$ & $13(56 \%)$ \\
Mortality $(n)$ & $21(19 \%)$ & $10(34 \%)$ & 9 \\
MM progression $(n)$ & 20 & 7 & 4 \\
Non-MM related $(n)$ & 1 & 3 & $2(20 \%)$ \\
Disease status at last follow-up & & $13(68 \%)$ & $1(10 \%)$ \\
CR $(n)$ & $40(49 \%)$ & $2(11 \%)$ & $1(10 \%)$ \\
VGPR $(n)$ & $23(28 \%)$ & $3(16 \%)$ & $6(60 \%)$ \\
PR $(n)$ & $5(6 \%)$ & $1(5 \%)$ & \\
Refractory/stable $(n)$ & $14(17 \%)$ & $n$ & \\
\hline
\end{tabular}

Three patients over 65 years had MEL100 as conditioning regimen: one patient for maintaining renal insufficiency after induction therapy; one patient for reduced number of cells for infusion $\left(1.6 \times 10^{6} \mathrm{CD} 34+\right.$ cells $\left./ \mathrm{kg}\right)$; and another patient for subjective evaluation of frailty. Two younger patients had conditioning with MEL140, both for persistent creatinine clearance $\leq 40 \mathrm{~mL} / \mathrm{min}$ 
Graph 1 Deepening of response after transplant according to age. a Transplanted patients $\leq 65$ years old; $\mathbf{b}$ transplanted elderly patients

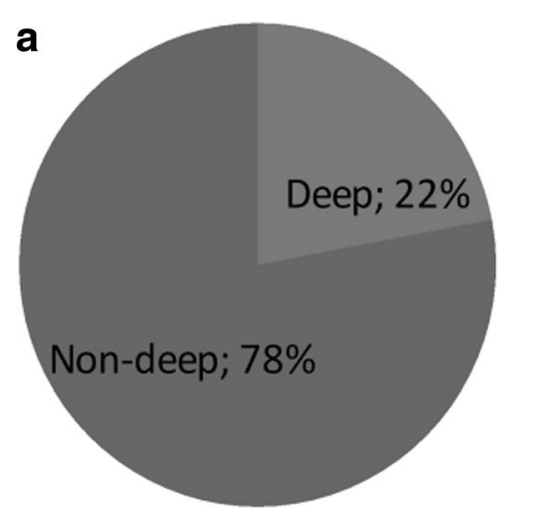

additionally, in another study, Muchtar et al. [30] showed evidence of decreasing infectious complications, transfusion needs, and inpatient days in this same age group from 1998 to 2015 , corroborating the favorable impact of supportive care and emphasizing the absence of a biological reason against age to ASCT eligibility.

In recent years, not only the feasibility of ASCT in the elderly has been disputed, but also its efficacy. Most studies are retrospective analysis [9, 11, 30, 32]; some are even before the era of novel agents as proteasome inhibitors (PI) and immunomodulatory drugs (IMIDs) [31, 33, 34], and others use matched pair comparison [35]. Notwithstanding its limitations, these studies found similar toxicity, TRM, and noninferiority in EFS, OS, or disease response to ASCT in elderly patients, even when considering a higher age threshold for older cohorts as 70 years $[30,32]$. In prospective studies $[13,33,36]$, patients aged over 65 years do not have an inferior outcome when compared to younger cohorts, considering ASCT is a safe and effective treatment for elderly and fit MM patients, either before [33] or in the present era of novel induction agents [36], which highlights the impact on global outcome that ASCT represents as a component on treatment algorithm in this group of patients [33]. Data is more challenging, considering that there are no randomized trials appropriate to conclude about ASCT in this particular population with the availability of newer effective drugs, namely monoclonal antibodies and new-generation PI or IMIDs [10, 37]. In our study, response after transplant, EFS, and OS did not differ according to age in transplanted patients. Elderly patients had the same benefit comparing to younger patients, either in deepening of response after autologous transplantation or in survival as EFS and OS were not significantly shorter. More so, when compared to the non-transplanted age-adjusted cohort, patients who were transplanted had a significant improvement in EFS and OS, despite having similar disease features. Even though our results seem favorable to transplanted elderly patients, this study shares some of the limitations mentioned above, specifically regarding its
Graph 2 OS according to age, median follow-up 30 months. Median 83 months in patients < 65 years old and 59 months in elderly patients $(p=0.15)$

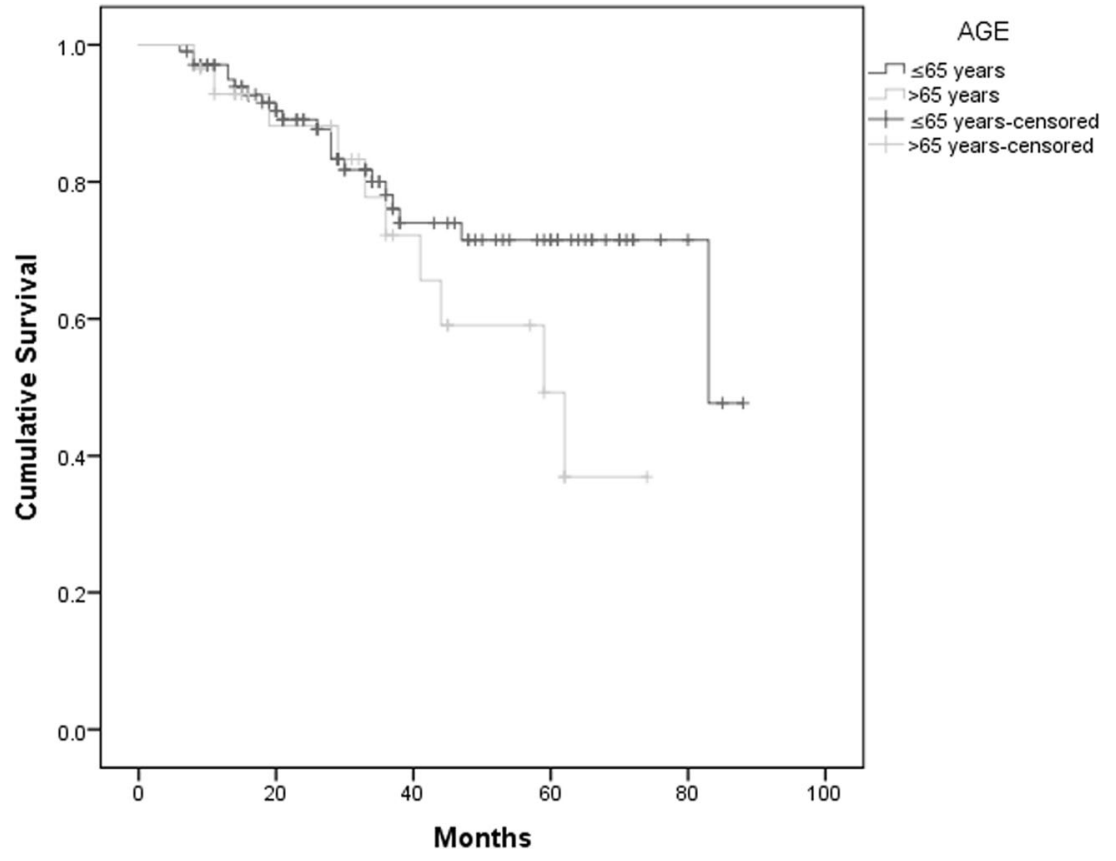


Graph 3 OS according to the dose of melphalan in the elderly group, median follow-up 30 months. Median 59 months in patients conditioned with reduced doses of melphalan vs 62 months in patients conditioned with high doses of melphalan $(p=0.73)$

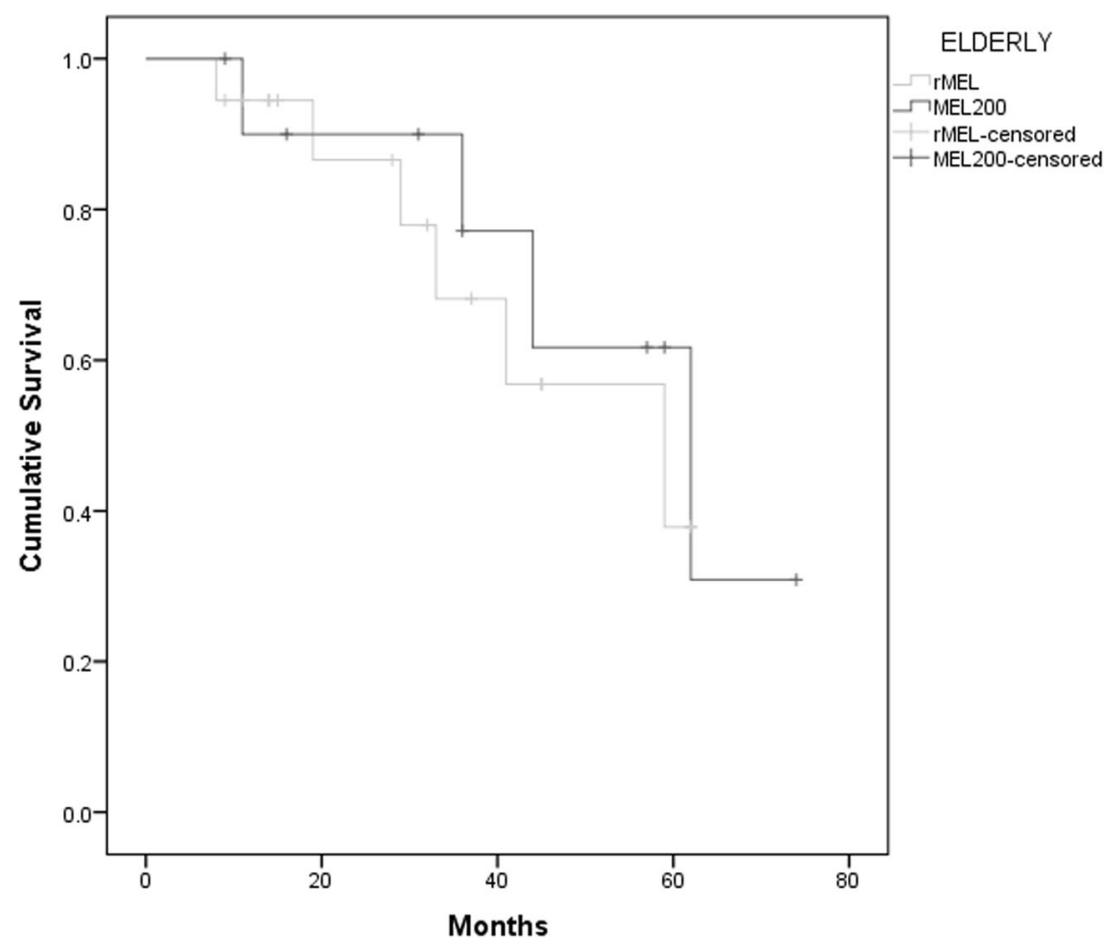

retrospective nature, non-randomization of patients, and the subjective categorization for transplant eligibility of elderly patients.

Another matter of discussion, when considering autologous transplantation in elderly patients, is the ideal dose of Melphalan before ASCT. In our analysis, we can see that elderly patients have more toxicity indeed in all parameters with higher doses of melphalan as in previously published data [9, 33]. There is no consensus in the MM community, as some authors defend the use of an intermediate dose of 100 or $140 \mathrm{mg} / \mathrm{m}^{2}$ demonstrating equal efficacy in CR rates, EFS, or OS but with lower toxicity [9, 14, 33, 35, 38] or even lower TRM [39]; other authors are in favor of MEL200 as they did not find any excessive toxicity or
Graph 4 OS of elderly patients according to transplant status, median follow-up 30 months. Transplanted group with a median of 59 months vs 30 months in non-transplanted group ( $p=$ 0.037)

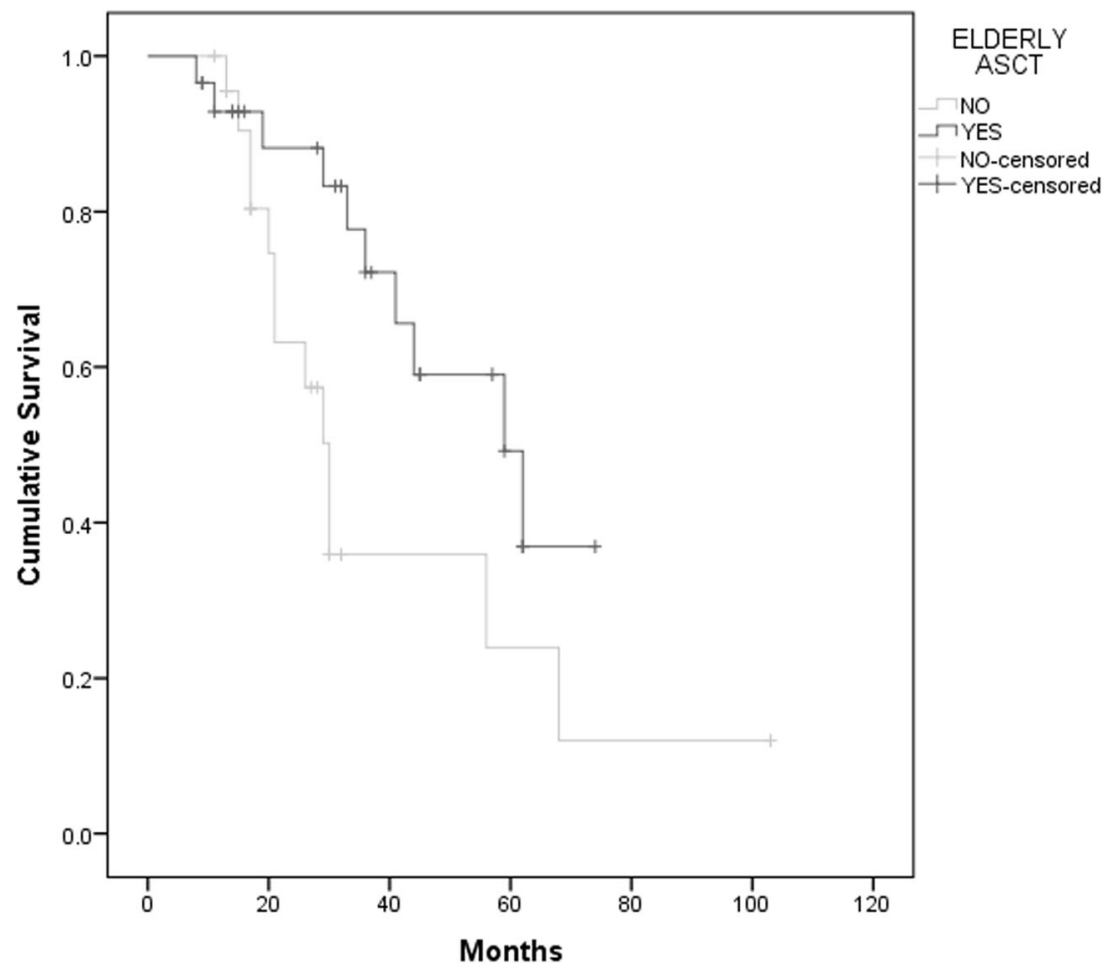


worse disease outcomes [11, 32, 40]; and others conclude that reduced doses of melphalan can benefit selected cases, but higher doses are preferred $[13,30]$. A recent prospective French study [36] demonstrated that there was no difference in myelotoxicity, infections, TRM, or disease response between MEL200 and MEL140, but it was noticed that patients treated with MEL200 had better EFS rate. In our analysis, even though it was not statistically significant, we also noted a trend to a better EFS rate in MEL200 elderly patients when compared to elderly patients treated with reduced doses of melphalan (62 months vs 45 months). However, once again, this was a retrospective analysis of a small and highly selected group of elderly patients with no standardized approach, which limits its statistical power.

\section{Conclusion}

It is suggested in the several aforementioned studies that age by itself is not a reliable prognostic factor for transplantation eligibility as autologous stem cell transplantation in elderly patients is a well-tolerated procedure with current and proper supportive and prophylactic care, with similar TRM, responses rate, EFS, and OS compared to younger patients. In our study, even after MEL200, elderly patients have clinical benefit with acceptable morbidity presenting similar EFS to the one obtained in younger patients, safeguarding that these are highly selected elderly patients.

Taking into account that optimal management of MM is vital for patient outcome, age should not be considered a major obstacle to transplantation. Eligibility should be based on biological fitness and comorbidities, ideally through geriatric assessment tools and comorbidity scores to avoid subjectivity, which was also an important limitation when analyzing our elderly patients.

Our study reflects real data on managing ASCT in elderly patients, offering them possibility of better results and better survival despite all the limitations we mentioned. From our results and revised published data to date, we may argue that ASCT is an essential step of MM treatment and should be offered as a treatment option regardless of age. However, there is a need to include elderly patients in transplant randomized trials to determine a survival benefit in an era of constant newer and effective drugs available.

Author's contributions CM performed data collection, wrote the statistical analysis plan, cleaned and analyzed the data, performed interpretation of data results, and drafted and revised the paper. TM performed data collection, performed interpretation of data results, and drafted and revised the paper. JP, EA, and JEG revised the drafted paper. RB and FT proposed and supervised this study and revised the drafted paper.

\section{Compliance with ethical standards}

This study has been evaluated and approved by our ethics committee, the Ethics Committee for Health of Centro Hospitalar de São João/Faculty of Medicine of Oporto University.

Conflict of interest The authors declare that they have no conflict of interest.

Open Access This article is distributed under the terms of the Creative Commons Attribution 4.0 International License (http:// creativecommons.org/licenses/by/4.0/), which permits unrestricted use, distribution, and reproduction in any medium, provided you give appropriate credit to the original author(s) and the source, provide a link to the Creative Commons license, and indicate if changes were made.

\section{References}

1. Bergin K, McQuilten Z, Moore E, Wood E, Spencer A (2017) Myeloma in the real world: what is really happening? Clin Lymphoma Myeloma Leuk 17(3):133-144

2. Turesson I, Velez R, Kristinsson SY, Landgren O (2010) Patterns of multiple myeloma during the past 5 decades: stable incidence rates for all age groups in the population but rapidly changing age distribution in the clinic. Mayo Clin Proc 85(3):225-230

3. Brenner H, Gondos A, Pulte D (2008) Recent major improvement in long-term survival of younger patients with multiple myeloma. Blood 111(5):2521-2526

4. Kristinsson SY, Landgren O, Dickman PW, Derolf AR, Björkholm M (2007) Patterns of survival in multiple myeloma: a populationbased study of patients diagnosed in Sweden from 1973 to 2003. J Clin Oncol 25(15):1993-1999

5. Attal M, Harousseau JL, Stoppa AM, Sotto JJ, Fuzibet JG, Rossi JF, Casassus P, Maisonneuve H, Facon T, Ifrah N, Payen C, Bataille R (1996) A prospective, randomized trial of autologous bone marrow transplantation and chemotherapy in multiple myeloma. Intergroupe Français du Myélome. N Engl J Med 335(2):91-97

6. Barlogie B, Jagannath S, Desikan KR, Mattox S, Vesole D, Siegel D, Tricot G, Munshi N, Fassas A, Singhal S, Mehta J, Anaissie E, Dhodapkar D, Naucke S, Cromer J, Sawyer J, Epstein J, Spoon D, Ayers D, Cheson B, Crowley J (1999) Total therapy with the tandem transplant for newly diagnosed multiple myeloma. Blood 93(1):55-65

7. Child JA, Morgan GJ, Davies FE, Owen RG, Bell SE, Hawkins K, Brown J, Drayson MT, Selby PJ, Medical Research Council Adult Leukaemia Working Party (2003) High-dose chemotherapy with hematopoietic stem-cell rescue for multiple myeloma. N Engl $\mathrm{J}$ Med 348(199):1875-1883

8. Merz M, Neben K, Raab MS, Sauer S, Egerer G, Hundemer M, Hose D, Kunz C, Heiß C, Ho AD, Goldschmidt H, Hillengass J (2014) Autologous stem cell transplantation for elderly patients with newly diagnosed multiple myeloma in the era of novel agents. Ann Oncol 25(1):189-195

9. Cohen YC, Zuckerman T, Yeshurun M, Perez G, Magen H, Henig I, Levi I, Shargian L, Trestman S, Rouvio U, Naparstek E, GanonElazar E, Avivi I, Ram R (2017) Efficacy and safety of autologous hematopoietic cell transplantation in elderly patients with multiple myeloma: a retrospective national multisite cohort study. Ann Hematol 96(2):271-278

10. Facon T, Mary JY, Hulin C, Benboubker L, Attal M, Pegourie B, Renaud M, Harousseau JL, Guillerm G, Chaleteix C, Dib M, Voillat L, Maisonneuve H, Troncy J, Dorvaux V, Monconduit M, Martin 
C, Casassus P, Jaubert J, Jardel H, Doyen C, Kolb B, Anglaret B, Grosbois B, Yakoub-Agha I, Mathiot C, Avet-Loiseau H (2007) Melphalan and prednisone plus thalidomide versus melphalan and prednisone alone or reduced-intensity autologous stem cell transplantation in elderly patients with multiple myeloma (IFM 99-06): a randomized trial. Lancet 370(9594):1209-1218

11. Siegel DS, Desikan KR, Mehta J, Singhal S, Fassas A, Munshi N, Anaissie E, Naucke S, Ayers D, Spoon D, Vesole D, Tricot G, Barlogie B (1999) Age is not a prognostic variable with autotransplants for multiple myeloma. Blood 93(1):51-54

12. Auner HW et al (2015) Trends in autologous hematopoietic cell transplantation for multiple myeloma in Europe: increased use and improved outcomes in elderly patients in recent years. Bone Marrow Transplant 50(2):209-215

13. Sharma M, Zhang MJ, Zhong X, Abidi MH, Akpek G, Bacher U, Callander NS, Dispenzieri A, Freytes CO, Fung HC, Gale RP, Gasparetto C, Gibson J, Holmberg LA, Kindwall-Keller TL, Klumpp TR, Krishnan AY, Landau HJ, Lazarus HM, Lonial S, Maiolino A, Marks DI, Mehta P, Mikhael JR, Nishihori T, Olsson R, Ramanathan M, Roy V, Savani BN, Schouten HC, Scott E, Tay J, To LB, Vesole DH, Vogl DT, Hari P (2014) Older patients with myeloma derive similar benefit from autologous transplantation. Biol Blood Marrow Transplant 20(11):1796-1803

14. Ozaki S, Shimizu K (2014) Autologous stem cell transplantation in elderly patients with multiple myeloma: past, present, and future. Biomed Res Int 2014:1-7. https://doi.org/10.1155/2014/394792

15. Sanchez L, Sylvester M, Parrondo R, Mariotti V, Eloy JA, Chang VT (2017) In-hospital mortality and post-transplantation complications in elderly multiple myeloma patients undergoing autologous hematopoietic stem cell transplantation: a population-based study. Biol Blood Marrow Transplant 23:1203-1207. https://doi.org/10. 1016/j.bbmt.2017.03.012

16. Dumontet C, Ketterer N, Espinouse D, Neidhardt EM, Moullet I, Thieblemont C, Salles G, Coiffier B (1998) Reduced progressionfree survival in elderly patients receiving intensification with autologous peripheral blood stem cell reinfusion for multiple myeloma. Bone Marrow Transplant 21:1037-1041. https://doi.org/10.1038/sj. bmt.1701232

17. Merz M, Jansen L, Castro FA, Hillengass J, Salwender H, Weisel K, Scheid C, Luttmann S, Emrich K, Holleczek B, Katalinic A, Nennecke A, Straka C, Langer C, Engelhardt M, Einsele H, Kröger N, Beelen D, Dreger P, Brenner H, Goldschmidt H, GEKID Cancer Survival Working Group and the DRST (2016) Survival of elderly patients with multiple myeloma-effect of upfront autologous stem cell transplantation. Eur J Cancer 62:1-8

18. Klepin HD, Hurd D (2006) Autologous transplantation in elderly patients with multiple myeloma: are we asking the right questions? Bone Marrow Transplant 38:585-592. https://doi.org/10.1038/sj. bmt. 1705486

19. Costa LJ, Zhang MJ, Zhong X, Dispenzieri A, Lonial S, Krishnan A, Freytes C, Vesole D, Gale RP, Anderson K, Wirk B, Savani BN, Waller EK, Schouten H, Lazarus H, Meehan K, Sharma M, Kamble R, Vij R, Kumar S, Nishihori T, Kindwall-Keller T, Saber W, Hari PN (2013) Trends in utilization and outcomes of autologous transplantation as early therapy for multiple myeloma. Biol Blood Marrow Transplant 19(11):1615-1624

20. Wildes TM, Finney JD, Fiala M, Gao F, Vij R, Stockerl-Goldstein K, Carson KR, Mikhael J, Colditz G (2015) High-dose therapy and autologous stem cell transplant in older adults with multiple myeloma. Bone Marrow Transplant 50(8):1075-1082

21. Ozaki S, Harada T, Saitoh T, Shimazaki C, Itagaki M, Asaoku H, Kuroda Y, Chou T, Yoshiki Y, Suzuki K, Murakami H, Hayashi K, Mina R, Palumbo A, Shimizu K, Japanese Society of Myeloma; European Myeloma Network (2014) Survival of multiple myeloma patients aged 65-70 years in the era of novel agents and autologous stem cell transplantation. A multicenter retrospective collaborative study of the Japanese Society of Myeloma and the European Myeloma Network. Acta Haematol 132(2):211-219

22. Kumar SK, Dispenzieri A, Lacy MQ, Gertz MA, Buadi FK, Pandey S, Kapoor P, Dingli D, Hayman SR, Leung N, Lust J, McCurdy A, Russell SJ, Zeldenrust SR, Kyle RA, Rajkumar SV (2014) Continued improvement in survival in multiple myeloma: changes in early mortality and outcomes in older patients. Leukemia 28(5): $1122-1128$

23. Greipp $P$ et al (2005) International Staging System for multiple myeloma. J Clin Oncol 23:3412-3420. https://doi.org/10.1200/ JCO.2005.04.242

24. Durie BG, Salmon SE (1975) A clinical staging system for multiple myeloma. Correlation of measured myeloma cell mass with presenting clinical features, response to treatment, and survival. Cancer 36(3):842-854

25. National Cancer Institute (2010) Common Terminology Criteria for Adverse Events (CTCAE). Version 4.0. Publication No. 09-5410

26. Kumar S, Paiva B, Anderson KC, Durie B, Landgren O, Moreau P, Munshi N, Lonial S, Bladé J, Mateos MV, Dimopoulos M, Kastritis E, Boccadoro M, Orlowski R, Goldschmidt H, Spencer A, Hou J, Chng WJ, Usmani SZ, Zamagni E, Shimizu K, Jagannath S, Johnsen HE, Terpos E, Reiman A, Kyle RA, Sonneveld P, Richardson PG, McCarthy P, Ludwig H, Chen W, Cavo M, Harousseau JL, Lentzsch S, Hillengass J, Palumbo A, Orfao A, Rajkumar SV, Miguel JS, Avet-Loiseau H (2016) International Myeloma Working Group consensus criteria for response and minimal residual disease assessment in multiple myeloma. Lancet Oncol 17(8):e328-e346

27. IBM Corp. Released (2011) IBM SPSS Statistics for Windows, Version 20.0. IBM Corp, Armonk

28. Rajkumar S et al (2014) International Myeloma Working Group updated criteria for the diagnosis of multiple myeloma. Lancet Oncol 15:e538-e548. https://doi.org/10.1016/S1470-2045(14) 70442-5

29. Mikhael JR, Dingli D, Roy V, Reeder CB, Buadi FK, Hayman SR, Dispenzieri A, Fonseca R, Sher T, Kyle RA, Lin Y, Russell SJ, Kumar S, Bergsagel PL, Zeldenrust SR, Leung N, Drake MT, Kapoor P, Ansell SM, Witzig TE, Lust JA, Dalton RJ, Gertz MA, Stewart AK, Rajkumar SV, Chanan-Khan A, Lacy MQ, Mayo Clinic (2013) Management of newly diagnosed symptomatic multiple myeloma: updated Mayo Stratification of Myeloma and RiskAdapted Therapy (mSMART) consensus guidelines 2013. Mayo Clin Proc 88(4):360-376

30. Muchtar E, Dingli D, Kumar S, Buadi FK, Dispenzieri A, Hayman SR, Wolf RC, Gastineau DA, Chakraborty R, Hogan WJ, Leung N, Kapoor P, Lacy MQ, Rajkumar SV, Gertz MA (2016) Autologous stem cell transplant for multiple myeloma patients 70 years or older. Bone Marrow Transplant 51(11):1449-1455

31. El Cheikh J et al (2011) Age at transplantation and outcome after autologous stem cell transplantation in elderly patients with multiple myeloma. Hematol Oncol Stem Cell Ther 4(1):30-36

32. Bashir Q, Shah N, Parmar S, Wei W, Rondon G, Weber DM, Wang M, Orlowski RZ, Thomas SK, Shah J, Qureshi SR, Dinh YT, Popat U, Anderlini P, Hosing C, Giralt S, Champlin RE, Qazilbash MH (2012) Feasibility of autologous hematopoietic stem cell transplant in patients aged $\geq 70$ years with multiple myeloma. Leuk Lymphoma 53(1):118-122

33. Straka C, Liebisch P, Salwender H, Hennemann B, Metzner B, Knop S, Adler-Reichel S, Gerecke C, Wandt H, Bentz M, Bruemmendorf TH, Hentrich M, Pfreundschuh M, Wolf HH, Sezer O, Bargou R, Jung W, Trümper L, Hertenstein B, Heidemann E, Bernhard H, Lang N, Frickhofen N, Hebart H, Schmidmaier R, Sandermann A, Dechow T, Reichle A, Schnabel B, Schäfer-Eckart K, Langer C, Gramatzki M, Hinke A, Emmerich B, Einsele H (2016) Autotransplant with and without induction 
chemotherapy in older multiple myeloma patients: long-term outcome of a randomized trial. Haematologica 101(11):1398-1406

34. Sirohi B, Powles R, Treleaven J, Mainwaring P, Kulkarni S, Pandha H, Bhagwati N, Horton C, Singhal S, Mehta J (2000) The role of autologous transplantation in patients with multiple myeloma aged 65 years and over. Bone Marrow Transplant 25(5):533-539

35. Kumar SK, Dingli D, Lacy MQ, Dispenzieri A, Hayman SR, Buadi FK, Rajkumar SV, Litzow MR, Gertz MA (2008) Autologous stem cell transplantation in patients of 70 years and older with multiple myeloma: results from a matched pair analysis. Am J Hematol 83(8):614-617

36. Garderet L, Beohou E, Caillot D, Stoppa AM, Touzeau C, Chretien ML, Karlin L, Moreau P, Fontan J, Blaise D, Polge E, Gueye MS, Ikhlef S, Marjanovic Z, Labopin M, Mohty M (2016) Upfront autologous stem cell transplantation for newly diagnosed elderly multiple myeloma patients: a prospective multicenter study. Haematologica 101(11):1390-1397
37. Palumbo A et al (2004) Intermediate-dose melphalan improves survival of myeloma patients aged 50 to 70 : results of a randomized controlled trial. Blood 104(10):3052-3057

38. Palumbo A, Bringhen S, Bertola A, Cavallo F, Falco P, Massaia M, Bruno B, Rus C, Barbui A, Caravita T, Musto P, Pescosta N, Rossini F, Vignetti M, Boccadoro M (2004) Multiple myeloma: comparison of two dose-intensive melphalan regimens (100 vs $200 \mathrm{mg} / \mathrm{m}(2))$. Leukemia 18(1):133-138

39. Badros A, Barlogie B, Siegel E, Morris C, Desikan R, Zangari M, Fassas A, Anaissie E, Munshi N, Tricot G (2001) Autologous stem cell transplantation in elderly multiple myeloma patients over the age of 70 years. Br J Haematol 114(3):600-607

40. Desai A, Beitinjaneh A, Ramdial J, Ali R, Lekakis L, Pereira D, Kimble E, Florou V, Bravo G, Goodman M, Byrnes JJ, Jimenez AM, Saneeymehri S, Komanduri KV (2017) Safety of high-dose melphalan $(200 \mathrm{Mg} / \mathrm{M} 2)$ as conditioning for autologous stem cell transplantation for myeloma in elderly patients. Biol Blood Marrow Transplant 23:S133-S134. https://doi.org/10.1016/j.bbmt.2016.12.250 